\title{
Öğretmen Adaylarının Merak ve Keşfetme Algıları ile Okuma Alışkanlığına Yönelik Tutumları Arasındaki İlişki
}

\author{
Şahin KAPIKIRAN \\ Pamukkale Üniversitesi, Eğitim Bilimleri Bölümü, Denizli \\ skkiran@pau.edu.tr \\ ORCID ID: http://orcid.org/0000-0002-9693-7660 \\ Fatma SUSAR KIRMIZI \\ Pamukkale Üniversitesi, Temel Eğitim Bölümü, Denizli \\ fsusar@pau.edu.tr \\ ORCID ID: http://orcid.org/0000-0002-0426-1908
}

\begin{tabular}{lr} 
Araştırma Makalesi & DOI: 10.31592/aeusbed.585328 \\
\hline Geliş Tarihi: 01.07.2019 & Revize Tarihi: 12.09.2019 \\
Atıf Bilgisi & \\
Kapıkıran, Ş. ve Susar Kırmılizı, F. (2019). Öğretmen adaylarının merak ve keşfetme algıları ile okuma \\
$\begin{array}{l}\text { alışkanlığına yönelik tutumları arasındaki ilişki. Ahi Evran Üniversitesi Sosyal Bilimler Enstitüsü Dergisi, 5(2), } \\
\text { 251-265. }\end{array}$
\end{tabular}

ÖZ

İnsanın doğasında var olan okuma duygusu onu keşfetmeye yönlendirirken icatlar ve yenilikler üretmesine de yardımcı olmuştur. Okuma alışkanlığı, merak duygusunun gelişmesinde oldukça önemli bir role sahiptir. Okuma, bireyin kendi kişiliğini, doğrularını değerlerini oluşturmasında etkili olduğu gibi olayları değerlendirmede farklı bakış açıları kazanmasında da yardımcı olur. Öğretmen adaylarında var olan okuma alışkanlığı ve merak duygusu mesleğe başladıktan sonra öğrencilerin kimlik gelişimine de olumlu yönde etki edebilmektedir. $\mathrm{Bu}$ araştırmanın amacı okulöncesi ve sınıf öğretmenliği programlarında öğrenim gören öğretmen adaylarının merak ve keşfetmeye ilişkin algıları ile okuma alışkanlığına yönelik tutumları arasındaki ilişkiyi incelemektir. Araştırmanın çalışma grubu, Eğitim Fakültesi Sınıf Öğretmenliği ve Okul Öncesi Eğitimi programlarında, 1. ve 3. sınıfta öğrenim görmekte olan 222 (167 kadın, 55 erkek) öğretmen adayıdır. Araştırma verilerinin elde edilmesinde "Merak ve Keşfetme Ölçeği (MK)" ile "Öğretmen Adaylarının Kitap Okuma Alışkanlığına Yönelik Tutum Ölçeği (ÖRAKOT)" kullanılmıştır. Elde edilen sonuçlara göre, öğretmen adaylarının merak ve keşfetme algıları ile kitap okuma alışkanlığına yönelik tutumları arasında ortalama düzeyde anlamlı bir ilişki bulunmuştur. Kadın öğrencilerin kitap okuma alışkanlığına yönelik tutumları erkek öğrencilerin tutumlarına oranla daha olumludur. Okuma alışkanlığına yönelik tutum az okuyan öğrencilere göre çok okuyanlarda daha yüksektir.

Anahtar Kelimeler: Merak, okuma tutumu, öğretmen adayı, korelasyonel model.

\section{Pre-service Teachers' Perceptions of Curiosity and Discovery the Relationship Between Attitudes Towards Reading Habits}

\begin{abstract}
The sense of reading that is inherent in man has led him to discover and help him to invent and innovate. Reading habits play an important role in the development of curiosity. Reading is not only effective in creating one's own personality and values, but also helps to gain different perspectives in evaluating events. The pre-service reading habits and curiosity of the prospective teachers have a positive effect on the identity development of the students after they have started their profession. The aim of this study is to investigate the relationship between pre-school and primary school teachers' perceptions of curiosity and discovery and their attitudes towards reading habits. The study group of the study consisted of 222 (167 female, 55 male) students in the 1st and 3rd grade in the Faculty of Education Classroom and Preschool Education programs. In obtaining the research data, Kashdan et al. (2009) developed "Curiosity and Exploration Scale (CE)" and Susar developed by Susar Kırmızı (2012) "Attitude Scale for Prospective Teachers' Reading Habits (ASPTRH)." According to the results, it was found that there was a significant relationship between the preservice teachers' perceptions of curiosity and discovery and their attitudes towards reading books. Female students 'attitudes towards reading habits are more positive than male students' attitudes. Attitudes towards reading habits are higher than those who read more than those who read less.
\end{abstract}

Keywords: Curiosity, reading attitude, prospective teachers, correlational model. 


\section{Giriş}

İnsanoğlu öğrenmeye merak ederek başlamıştır. Merak güdüsü bilme isteğine k1lavuzluk etmiştir. Birey hayata gözlerini açtığı andan itibaren sürekli bir şekilde bir şeyler öğrenmek çaba gösterir. Çünkü, insan türü, diğer canlılardan farklı olarak, dünyaya yüksek düzeyde merak güdüsü ile gelir. Öğrenme gereksinimi hiç bitmez ve ölene kadar devam eder. Merak öğrenmenin, bilgi hazinesinin anahtarı konumundadır.

Merak, kişilik psikolojisi içinde dikkati çeken bir özellik olarak ilgi odağı olmuştur. Bireyi yeni bir alan çevirir ve keşfetmesini sağlar (Kashdan, Gallagher, Silvia, Winterstein, Breen, Terhar ve Steger, 2009). İnsanın hayatta kalması ve büyümesi için kritik öneme sahiptir. Yaygın olarak belirsiz, karmaşı ve yeni olayları takip etme, tanıma ve keşfetme arzusu olarak tanımlanabilir. Merak tüm canlıların doğasında var olan güçlü bir güdüdür (Gerber, 2009). İnsan zihnindeki sorulara, belirsizliklere, karmaşılıllıklara ve çelişkilere son vermek için çaba gösterir. Bu çaba ile araştırır, keşfeder, öğrenir. Merak, insanın ilerlemesine yardımcı olur.

Birçok deneysel ve görgül araştırmaya göre akademik süreçte merak, ebeveynlerin çocuklarının akademik davranışlarına ilişkin tutumlarını (Endsley, Hutcherson, Garner ve Martin, 1979, Akt. Acun Kapıkıran ve Kabasakal, 2013); düşünme gereksinimi yaratmayı (Olson, Camp ve Fuller, 1984), yüksek akademik performansı oluşturmayı (Eren, 2009) ve hedef yönelimli olmayı olumlu olarak etkilemektedir (Kashdan vd., 2009). Merak güdüsünün temelinde, öğrenme potansiyeli bulunan bir durumu anlamaya çalışmak vardır. Birey merakla yeni deneyimler arama arzusu gösterir ve ne olacağını görmek ister. Nasıl tepki verildiğini keşfetmeye çalışır (Kashdan, Stiksma, Disabato, McKnight, Bekier, Kaji ve Lazarus, 2018). Bununla beraber, merakın birey üzerindeki kısa erimli işlevlerinden birisi daha fazla öğrenmesini, keşfetmesini ve bir şeye dikkatini yoğunlaştırmasını kolaylaştırmaktır. Uzun erimli olarak ise bilgi ve yeterlik sağlamaktadır (Kashdan ve Silvia, 2009). Merak keşfetmeyi ya da keşfi sürdürme eylemini tetiklemektedir.

İnsanlar merak ve keşfetme duygusunu gidermek için farklı yollar denerler. Kimi zaman gezi gözlem aracılığı ile meraklarını gidermeye çalışırlar. Çoğu zaman bireyler bir duruma ilişkin merakını gidermede gezi gözlem gibi olanaklara sahip olamazlar. Öğrenme gereksiniminin giderilmesinde gezi gözlem kadar kitaplar da etkili olmuştur. Teknolojinin gelişmesi ile birlikte bireylerin meraklarını gidermede sanal ortam önemli bir yer tutmuştur. Bireyler merak ettikleri konuları sanal ortamda okumaya yönelseler de daha derin şekilde bir konuya ilişkin bilgi edinme gereksinimini basılı kitaplar ve e-kitaplarla giderebilmektedir. Gurning ve Siregar (2017) yaptıkları deneysel bir çalışmada, merakı yüksek olan öğrencilerin okuduğunu anlama düzeyinin merakı düşük olanlara göre daha yüksek olduğunu bulmuştur.

Okuma yazılı, basılı, oyma ya da kabartma türündeki simgelerden anlam çıkarma sürecidir. Oğuzkan'a (1997) göre ise sözcükleri, cümledeki anlamıyla birlikte yazıyı oluşturan unsurlarla algılama ve kavrama işidir. Okuma sırasında yazı tanınır, yazıdan bir anlam çıkarılır ve önceki yaşantılarla ilişkilendirilerek anlam yapılandırılır. Okuma zihinsel bir süreçtir.

Okumak, doğduğu andan itibaren eğitim süreci geçiren bireyin en kolay ve etkili öğrenme yollarından birisidir. Çağdaş toplumların okuma oranı yüksek olduğu gibi okumanın olumlu yönlerini her alanda da yaşamaktadır. Okuma alışkanlığ 1 yeterince gelişmemiş toplumlar bilimde, sanatta olduğu gibi yaşamın diğer alanlarınada da üretken olamamaktadır. Çünkü okuyan bireyler olayların iç yüzünü görmede, eleştirmede, sorgulamada, hak aramada, başkalarının farklılıklarına saygı göstermede daha başarılı olmaktadır. Bu nedenle okuma alışkanlığının geliştirilmesi çağdaş bir toplum olma yolunda ilerlemek için oldukça önemlidir.

Okuma alışkanlığ 1 , bireysel özgüveni, ahlaki ve entelektüel gelişimi arttırır. Okuma alışkanlığı olan bir öğrenci kaçınılmaz olarak akademik çabalarında başarılı olacaktır. Okuma, bireyin ufkunu genişletirken, ilgi duyduğu alanı belirlemesinde yardımcı olur; kendini, diğer insanları ve dünyayı daha iyi anlayabileceği bir deneyim sağlar (Akande ve Oyedapo, 2018; Kushmeeta, 2013). Okuma 
alışkanlığını kazandırmada en etkili kurumlardan birisi de okuldur. Okulda öğretmen tarafından okuma isteği uyandıracak kaynaklarla karşılaşmak bu alışkanlığın gelişmesinde oldukça etkilidir. Okumaya yönelik ilginin arttırılmasında ve okuma alışkanlığının geliştirilmesinde okul önemli bir rol oynamaktadır (Applegate ve Applegate, 2004; Batur, Gülveren ve Bek, 2010; Mckool ve Gespass, 2009). Öğretmenler eğitim sistemin etkili birer ögesi olan öğretmenler yeni, yaratıcı ve sıra dış1 uygulamalarla öğrencileri okumaya yönlendirebilir. Öğrencileri okumaya sevk edici çalışmalar yaşam boyu okuyan bireylerin yetiştirilmesinde oldukça etkili olmaktadır (Stanfield (2006). Öğretmenlerin okumaya teşvik etmek için yaratıcı yollar bulmaya çalışması ve öğrencilerini yaşam boyu okur olmaya özendirmesi onların okuma güdülerini arttırmaktadır. Okuma sertifikası, övgü gibi somut ancak maddi olmayan ödüller bu konuda oldukça etkili olabilmektedir. Teşvik edici davranışlar okumaya yönelik ilgiyi arttırabilmektedir (Edmunds ve Tancock, 2003; Guthrie ve Wigfield, 2000). Stanfield ilkokul üçüncü sınıf öğrencileri ile yaptığı araştırmada okumaya özendiricilerin okunacak kitap sayıs1 sabit kalmakta birlikte okumaya ilişkin istekliliği arttırdığını tespit etmiştir. Small (2009) "okuma teşvik programlarını" öğrencilerin uzun süreli okuma sevgisi geliştirmede etkili olabileceğine vurgu yapmaktadır. Bu tip programlar öğrencilerin sunulan listeden kitap seçmelerine, okuduklarını test etmelerine, puanlar almalarına izin vermekte ve öğrencilerin uzun süreli okuma davranışları geliştirmelerinde etkili olabilmektedir.

Okumanın insan için kişisel ve toplumsal olarak birçok faydası olduğu bilinen bir gerçektir. Okumanın bireyin kendini zihinsel olarak geliştirmesi, hayatına zenginlikler katması ve bakış açısını değiştirmesi gibi kişisel faydalarının yanı sıra topluma uyum sağlamasında, daha iyi ilişkiler kurarak sosyal yaşamın bir parçası olmasında ve yaşadığı ülkenin vatandaşı olarak sorumluluklarını yerine getirmesinde de faydası büyüktür (Korkmaz, 2008, s.71). Bunun için okumanın kişide alışkanlık hâline gelmesi gerekir.

Okuma alışkanlığı, bireyin okumayı bir gereklilik olarak görüp yaşam boyu sürekli, düzenli ve eleştirel olarak sürdürmesidir. Okuma alışkanlığı bireyin kelime hazinesini geliştirmesinde, başka bir dilin dilbilgisini anlamada da etkili olur. Duygusal gelişimin, sosyal katılımın, kültürel farkındalığın ve endüstriyel zekânın geliş̧mesini sağlar. Kitaplar, bireyin kendi gizli benliğini keşfetmesinin de yolunu açar. Okuma bireylerin olayları ve durumları daha iyi anlamasına, analiz etmesine ve sorgulamasina yardimc1 olur (Applegate ve Applegate, 2004; Chettri ve Rout, 2013; Shen, 2006 Wagner, 2002).

Okuma, çocuğun hayatta başarılı olması için öğrenmesi gereken en temel becerilerden biridir. Okuma alışkanlığı bireyin yaşam boyu öğrenmeyi gerçekleştirmesinde en etkili anahtarlardan birisidir. Yaşam boyu öğrenen olmak için okuma eylemini düzenli olarak gerçekleştirmek ve alışkanlık haline dönüştürmek (Odabaş, Odabaş ve Polat, 2008; Yılmaz, 1993). İyi okuma alışkanlıkları geliştirmek, çocuğun geleceği için sadece akademik olarak değil, günlük hayatta da çok önemlidir. Okumaya yönelik olarak olumlu tutumların kazandırılması okuma oranının artmasında etkili olabilir.

Tutum, belirli bir nesneye, kişiye, şeye veya olaya ilişkin bir dizi duygu, inanç ve davranışa atıfta bulunmaktır. Tutumlar devam edebilir zamanla değişim de gösterebilir (Chery, 2019). Davranışları yönlendiren ve bireyde bazen yargılara dönüşen durumlar, tutum olarak ifade edilir. Tutum doğrudan gözlenebilen bir özellik değildir (Chaiklin, 2011; Kağıtçıbaşı, 2006; Karahan, 2018). Tutumun bilişsel, duygusal, davranışsal olmak üzere 3 boyutu vardır ve bu boyutlar birbiri ile tutarlı bir ilişki içerisindedir. Birbirleri ile etkileşim halinde olan bu üç boyut birbirinden kesin olarak ayrı çizgilerle değerlendirilmezler. Tutumlar genellikle tecrübe veya eğitim sonucu ortaya çıkar ve davranış üzerinde güçlü bir etkiye sahip olabilir.

Okuma alışkanlığının gelişmesinde olumlu tutumlar oldukça önemlidir. Okumaya yönelik olumlu tutum geliştirmiş olan öğrenciler okumayı sever, değer verir ve okumanın öneminin farkına varırlar. Daha sık okuma eğiliminde oldukları gibi geniş bir yelpazede okurlar. Okuyarak anlama becerilerini ve öğrenme deneyimlerini geliştirebilirler. Ancak olumsuz okuma tutumu geliştirmiş bireyler okumadan kaçma eğilimindedirler. Okumak yerine farklı etkinliklere yönelmektedirler. Son yıllarda bu etkinliklerin başında sosyal medya kullanmı gelmektedir. Smith (1988), okumaya yönelik 
tutumu; "okuma ihtimalini artıran ya da azaltan, duyu ve duyguların da eşlik ettiği zihinsel bir durum" olarak tanımlamaktadır (Akt. Özdemir ve Akkaya, 2014),

İyi bir okuyucu okudukça merak eder merak ettikçe de daha çok okur hale gelecektir. Okumak her birey için vazgeçilmez derecede önemlidir. Ancak toplumun okuma alışkanlığını geliştirmede oldukça önemli rol oynayan öğretmenler için daha da önemlidir. Okuyan bir öğretmen öğrencilerinin merak güdüsünü ve okuma alışkanlığını geliştirmede etkili olabilir. Özellikle okul öncesi öğretmenleri ve hemen devamında eğitim yaşamının sınıf öğretmenleri bu konuda özel bir yere sahiptir. Okuma alışkanlığının ve merak güdüsünün geliştirilmesinde önemli bir rol oynayan sınıf öğretmeni ve okul öncesi öğretmenlerinin bu konudaki durumlarına ilişkin bilimsel bir değerlendirme yapılmasının anlamlı olacağından hareket edilmiştir. Tüm bunlara bağlı olarak öğretmen adaylarının merak ve okuma alışkanlıklarının bilimsel çalışmalarla ele alınması özel bir önem taşımaktadır. $\mathrm{Bu}$ araştırmanın amacı eğitim fakültesinde, okulöncesi ve sınıf öğretmenliği programlarında 1. ve 3 . sınıflarda öğrenim gören öğretmen adaylarının merak ve keşfetmeye ilişkin algıları ile okuma alışkanlığına yönelik tutumları arasındaki ilişkiyi incelemek; diğer taraftan öğretmen adaylarının merak ve keşfetme algıları ile okumaya yönelik tutumlarını farklı değişkenler açısından değerlendirmektir. Amaca bağlı olarak şu alt problemler oluşturulmuştur. Sınıf ve okul öncesi eğitimi programlarında öğrenim görmekte olan;

1. Öğretmen adaylarının merak ve keşfetme algıları ile kitap okuma alışkanlığına yönelik tutumları arasında ilişki var mıdır?

2. Öğretmen adaylarının merak ve keşfetme algıları ile okuma alışkanlıklarına yönelik tutumlarında

a) cinsiyet,

b) sinıf düzeyi

c) kitap okuma alışkanlıkları,

d)öğrenim gördükleri program değiş̧kenlerine göre anlamlı bir farklılık var mıdır?

\section{Yöntem}

Bu çalışmada keşfedici korelasyonel model benimsenmiştir. Korelasyonel araştırmalar iki ya da daha fazla değişken arasındaki ilişkilerin herhangi bir şekilde bu değişkenlere müdahale edilmeden incelendiği araştırmalardır. Keşfedici korelasyonel araştırmalarda ise değişkenler arası ilişkiler çözümlenmeye çalış1ır (Büyüköztürk, Kılıç Çakmak, Akgün, Karadeniz ve Demirel, 2012; Tekbıyık, 2015).

\section{Çalışma Grubu}

Bu çalışma 2018-2019 eğitim yılının bahar döneminde A Üniversitesi Eğitim Fakültesinin temel eğitim bölümünde, Sınıf Eğitimi $(n=118)$ ve Okul Öncesi Eğitimi $(n=104)$ Ana Bilim Dallarında yürütülmüştür. Araştırmanın verileri birinci sınıf 72 (\%32) ve üçüncü sınıf 150 (\%68) olmak üzere toplam 222 öğretmen adaylarından toplanmıştır. Katılımcıların, \%75'i kadın (167) ve \%25'i erkek (55) öğrencilerden oluşmuştur. Bu çalışmada eğitim fakültesine yeni başlamış olan 1. sınıf ile 3. Sınıfta öğrenim görmekte olan öğretmen adayalrının merak- keşfetme algıları ile okuma alışkanlığına yönelik tutumları incelenmek istenmiştir. $\mathrm{Bu}$ nedenle ilgili sınıf düzeyleri tercih edilmiştir. Araştırmanın yapıldığı fakültede gerçekleştirilen incelemelerde 4. sınıfta öğrenim görmekte olan öğretmen adaylarına ulaşmanın oldukça zor olduğu tespit edilmiştir. Öğretmen adaylarının öğretmenlik ataması sınavlarına hazırlandıkları için fakülte ile iletişimlerinin oldukça sınırlı olduğu (4. Sınıf derslerini üstten aldıkları için fakülteye sınırlı zamanlarda geldikleri, dersane ya da kursa gittikleri vb.) belirlenmiştir. Bu nedenle araştırma dışında tutulmalarının uygun olacağı düşüncesine ulaşılmıştır. 


\section{Veri Toplama Araçları}

Araştırma verilerinin elde edilemesinde Kashdan vd. (2009) tarafindan geliştirilen, Acun, Kapıkıran ve Kabasakal (2013) tarafından Türkçe'ye uyarlaması yapılan "Merak ve Keşfetme ÖlçeğiII (MK)" ile Susar Kırmızı (2012) tarafından geliştirilen "Öğretmen Adaylarının Kitap Okuma Alışkanlığına Yönelik Tutum Ölçeği (ÖRAKOT)" kullanılmıştır. Ayrıca katılımcılara, bu çalışmanın amacı doğrultusunda, cinsiyet, sınıf düzeyi, kitap okuma alışkanlığı ve öğrenim gördükleri programa ilişkin demografik bilgiler içeren bir kişisel bilgi formu da uygulanmıştır.

\section{Merak ve Keşfetme Ölçeği-II (MK)}

Kashdan vd. (2009) tarafından geliştirilen ölçek 10 maddeden oluşmaktadır. Ölçeğin faktör yapısı için hem açımlayıcı hem de doğrulayıcı faktör analizi yapılmıştır. Ölçek iki faktörlü bir yapıya sahiptir. Esneklik alt ölçeği (6 madde) bilgi ve yeni deneyim arama güdüsünü; belirsizliği kabul etme alt ölçeği (4 madde) ise belirsiz ve kestirilemez olanı keşfetme isteğini yansıtmaktadır. Ölçeğin doğrulayıcı faktör yapısına ilişkin olarak iyi ve mükemmele doğru değişen indeksler elde edilmiştir. Ölçeğin iki alt boyutunun birbirleriyle ilişkisi .85 bulunmuştur. Ölçeğin Cronbach's Alpha kat sayılarının .75 ile .86 arasında olduğu hesaplanmıştır. Merak ve Keşfetme Ölçeğinin-II (MK) Türkçeye uyarlanması Acun, Kapıkıran ve Kabasakal (2013) tarafından yapılmıştır. Uyarlama çalışması eğitim fakültesinde 105 erkek ve $218 \mathrm{kız}$ olmak üzere toplam 323 öğretmen adayı ile gerçekleştirilmiştir. Türkçe ölçek için hem açımlayıcı hem de doğrulayıcı faktör analizi yapılmıştır. Ölçeğin doğrulayıcı faktör analizi sonucunda, RMSEA $=.05$, SRMR $=.04$, CFI $=98$, NNFI $=.97$ ile iyi ve mükemmellik düzeyinde uyum değerlerinde olduğu saptanmıştır. Maddelerinin faktör yükleri ise .52 ile .76 arasında değişmektedir. Ölçeğin iç tutarlığı için $\alpha=.80$ olarak hesaplanmıştır. Ölçeğin test tekrar test güvenirliği $r=.76$ olarak bulunmuştur. Bu çalışma için ölçeğin cronbach's alpha güvenirlik katsayısı .83 olarak hesaplanmıştır.

\section{Öğretmen Adaylarının Kitap Okuma Alışkanlığına Yönelik Tutum Ölçeği (ÖRAKOT)}

Öğretmen adaylarının kitap okuma alışkanlığına yönelik tutumlarını belirlemek amacıyla Susar Kırmızı (2012) tarafından geliştirilen ve 34 maddeden oluşan Kitap Okuma Alışkanlığına Yönelik Tutum Ölçeği (ÖRAKOT) kullanılmıştır. Ölçeğin geçerlik ve güvenirlik çalışması 3. sınıfta öğrenim görmekte olan 784 katılımcı ile gerçekleştirilmiştir. Ölçek üç alt boyuttan oluşmakta olup bunlar "öğrenme gereksiniminin karşılanması ve eğlenme; kitap okuma alışkanlığının anlamı ve vazgeçilmezliği, kitap okuma alışkanlığının geliştirilmesi” şeklinde adlandırılmıştır. Ölçekte yer alan maddelerin faktör yük değerleri .54 ile .80 arasında değişmektedir. Ölçeğin cronbach's alpha güvenirlik katsayısı .95 olarak belirlenmiştir. Bu çalışma için cronbach's alpha güvenirlik katsayısı .89 olarak hesaplanmıştır.

\section{Verilerin Toplanması ve Çözümlenmesi}

Araştırma verilerinin elde edilmesi için belirlenmiş olan her iki ölçek araştırmacılar tarafından, okul öncesi eğitimi ve sınıf öğretmeni adaylarına, gönüllülük esasına göre aynı anda uygulanmıştır. Ölçekler uygulanmadan önce çalışmanın amacına ilişkin bilgi verilmiştir. Elde edilen veriler bilgisayar ortamına aktarılmıştır. Öğretmen adaylarının meraklarıyla okuma alışkanlıklarına yönelik tutumlarının incelendiği bu çalışmada, değişkenlerin analizinde öncelikli olarak, korelasyon analizi, Cronbach's Alpha, çarpıklık, basıklık, kolmogorov-simirnov, ortalama ve standart sapma gibi analizler yapılmıştır. Daha sonra değişkenler arasındaki farkı hesaplamak için t-testi analizi uygulanmıştır. Çalışmanın verilerinin analizi için SPSS 17.0 kullanılmıştır.

\section{Bulgular}

MK ve ÖRAKOT ölçeklerinden elde edilen puanlara t-testi analizi yapılmadan önce verilerin dağılımının normal olup olmadığını belirlemek amacıyla çarpıklık-basıklık ve Kolmogorov-Smirnov değerlerine bakılmıştır. 
Tablo 1

MK ile ÖRAKOT'a İlişskin Ortalama, Standart Sapma, Basılklk ve Çarpıklık Değerleri

\begin{tabular}{lcccc}
\hline Bağımlı Değişkenler & Çarpıklık & Basıklık & Mean & Std. Deviation \\
\hline Merak ve Keşfetme & .420 & -.344 & 10.387 & 3.391 \\
\hline $\begin{array}{l}\text { Öğretmen Adaylarının Kitap Okuma Alı̧skanlığına Yönelik } \\
\text { Tutumları }\end{array}$ & -.590 & -.005 & 15.887 & 2.949 \\
\hline
\end{tabular}

MK ile ÖRAKOT puanlarının normal dağılım gösterip göstermediğini belirlemek amacıyla çarpılık ve basıklık katsayıları hesaplanmıştır. Tablo 1'de de görüldüğü gibi değişkenlere ait puanlar normal dağılım göstermiştir. Çarpıklık ve basıklık değeri -1 ve +1 sınırları içerisinde kalıyorsa, puanların normal dağılım gösterdiği şeklinde yorumlanmaktadır (Büyüköztürk, 2012).

Tablo 2

MK ile ÖRAKOT'a İlişkin Kolmogorov-Smirnov Test Sonuçları

\begin{tabular}{|c|c|c|c|}
\hline Bağımlı Değişkenler & $\begin{array}{c}\mathrm{K}-\mathrm{S} \\
\mathrm{Z}\end{array}$ & df1 & $\mathrm{p}$ \\
\hline Merak ve Keşfetme & 1.010 & 222 & .259 \\
\hline $\begin{array}{l}\text { Öğretmen Adaylarının Kitap Okuma Alışkanlığına Yönelik } \\
\text { Tutumları }\end{array}$ & .773 & 222 & .589 \\
\hline
\end{tabular}

Bağımlı değişkenlere ait puanların normalliğini belirlemek için yapılan bir diğer normallik testi için Kolmogorov-Smirnov testi yapılmıştır. Tablo 2'de de görüldüğü gibi Kolmogorov-Smirnov testi sonuçlarına göre puanların normalliğe uygun olduğu saptanmıştır. Analizde hesaplanan p-değeri istatistiksel olarak anlamlı değilse anlamlılık düzeyinde puanların normal dağılımdan anlamlı sapma göstermediği şeklinde yorumlanmaktadır (Büyüköztürk, 2012).

Araştırmanın birinci alt problemi "Öğretmen adaylarının merak ve keşfetme algıları ile kitap okuma alışkanlığına yönelik tutumları arasında ilişki var mıdır?” şeklinde oluşturulmuştur. Bu alt probleme yanıt vermek amacı ile MK toplam puanları ve alt boyutlarının puanları ile ÖRAKOT toplam puanları ve alt boyutlarının puanları arasında korelasyon çözümlemesi uygulanmıştır. Elde edilen veriler Tablo 3 'te sunulmaktadır.

Tablo 3

Ögretmen Adaylarının MK Toplam ve Alt Boyutlarının Puanları ile ÖRAKOT Toplam ve Alt Boyutlarinin Puanları Arasındaki Korelasyonlar

\begin{tabular}{llllllll}
\hline & 1 & 2 & 3 & 4 & 5 & 6 & 7 \\
\hline 1.Esneklik & - & & & & & & \\
\hline 2.Belirsizliği Kabul Etme & $.54^{* *}$ & - & & & & & \\
\hline 3.MK Toplam & $.91^{* *}$ & $.85^{* *}$ & - & & & & \\
\hline 4.KOAG & $.29^{* *}$ & .05 & $.20^{* *}$ & - & & & \\
\hline 5. KOAAV & $.33^{* *}$ & .06 & $.24^{* *}$ & $.81^{* *}$ & - & & \\
\hline 6.ÖGKE & $.29^{* *}$ & .11 & $.24^{* *}$ & $.88^{* *}$ & .72 & - & \\
\hline 7.ÖRAKOT Toplam & $.32^{* *}$ & .06 & $.23^{* *}$ & $.98^{* *}$ & .90 & .90 & - \\
\hline p<.05*: p<.001** & & & & & & &
\end{tabular}

Not: 3. MK=Merak ve Keşfetme Ölçeği 4. KOAG = Kitap Okuma Alışkanlığının Geliştirilmesi; 5. KOAAV= Kitap Okuma Alıșkanlığının Anlamı ve Vazgeçilmezliği; 6. ÖGKE= Öğrenme Gereksinimin Karşılanması ve Eğlenme; 7. ÖRAKOT = Öğretmen Adaylarının Kitap Okuma Alışkanlığına Yönelik Tutum Ölçeği

Öğretmen adaylarının merak-keşfetme toplam puanları ile kitap okuma alışkanlığına yönelik tutumlarının toplam puanları arasında anlamlı ve orta düzeyde bir iliş̧ki $(\mathrm{r}=.23, \mathrm{p}<0.01)$ bulunmuştur. MK toplam puanları ile "kitap okuma alışkanlığının geliştirilmesi" alt boyutu puanları arasında $(\mathrm{r}=.20$; $\mathrm{p}<0.01)$, "kitap okuma alışkanlığının anlamı ve vazgeçilmezliği" puanları ile $(\mathrm{r}=.24 ; \mathrm{p}<0.01)$ "öğrenme gereksinimin karşılanması ve eğlenme" alt boyutları arasında orta düzeyde ve anlamlı bir ilişki $(r=.24 ; p<0.01)$ bulunmuştur. 
Alt boyutlar incelendiğinde merak-keşfetme ölçeğinin esneklik alt ölçeği ile okuma alışkanlığına yönelik tutum ölçeği toplam puanları arasında $(\mathrm{r}=.32 ; \mathrm{p}<0.01)$ orta düzeyde ve anlamlı bir ilişki olduğu görülmektedir. "Belirsizlik" alt boyutu ile "kitap okuma alışkanlığının geliştirilmesi" $(\mathrm{r}=.29 ; \mathrm{p}<0.01)$ alt boyutu arasında; "kitap okuma alışkanlığının anlamı ve vazgeçilmezliği" ( $\mathrm{r}=.33$; $\mathrm{p}<0.01)$ arasında; son olarak "öğrenme gereksinimin karşılanması ve eğlenme" alt boyutları $(\mathrm{r}=.29$; $\mathrm{p}<0.01)$ arasında orta düzeyde anlamlı bir ilişki olduğu tespit edilmiştir.

Alt boyutlar incelendiğinde MK'nin belirsizlik alt ölçeği ile ÖRAKOT'un toplam puanları ile kitap okuma alışkanlığının geliştirilmesi ile; kitap okuma alışkanlığının anlamı ve vazgeçilmezliği ile; öğrenme gereksinimin karşılanması ve eğlenme alt boyutları arasında anlamlı düzeyde bir ilişki bulunmamıştır.

Çalışmanın bağımlı değişkenleri (merak ve keşfetme algıları ve kitap okuma alışkanlığına yönelik tutumları ile bağımsız değişkenleri (cinsiyet, sınıf düzeyi, kitap okuma alışkanlığı ve öğrenim gördükleri program) arasında fark olup olmadığını belirlemek üzere bağımsız örneklem grubuna göre t-testi yapılmıştır. Cinsiyet değişkenine ilişkin olarak elde edilen veriler Tablo 4 'te verilmiştir.

Tablo 4

MK ve ÖRAKOT Puanlarının Cinsiyet Değişkenine Göre T-Testi Sonuçları

\begin{tabular}{|c|c|c|c|c|c|c|c|}
\hline Değişkenler & Cinsiyet & $\mathrm{N}$ & $\overline{\mathrm{x}}$ & $\mathrm{Sd}$ & SE & $\mathrm{t}$ & $\mathrm{p}$ \\
\hline \multirow[t]{2}{*}{ MK } & Kadın & 167 & 30.48 & 6.53 & .50 & -4.283 & 001 \\
\hline & Erkek & 55 & 33.78 & 6.19 & .83 & & \\
\hline \multirow[t]{2}{*}{ ÖRAKOT } & Kadın & 167 & 124.84 & 16.74 & 1.29 & 3.151 & 001 \\
\hline & Erkek & 55 & 116.52 & 17.68 & 2.38 & & \\
\hline
\end{tabular}

Cinsiyetler arasında merak ve okuma alışkanlıkları tutum puanları bakımından fark olup olmadığını belirlemek üzere yapılan t- testi sonucunda, anlamlı düzeyde fark bulunmuştur. Öğretmen adaylarının merak puanları bakımından erkeklerin $(\overline{\mathrm{x}}=33.78, \mathrm{Sd}=6.19)$ kadınlardan $(\overline{\mathrm{x}}=30.48, \mathrm{Sd}$ $=6.53$ ) daha yüksek puanlara sahip olduğu saptanmıştır $[\mathrm{t}=-4.283 ; \mathrm{P}<.01]$. Diğer bir deyişle, erkekler kadınlardan daha meraklıdırlar. Daha fazla yeni şeyleri keşfetmek istemektedirler. Okuma alışkanlığına yönelik tutum bakımından kadınların $(\overline{\mathrm{x}}=124.844, \mathrm{Sd}=16.742)$ erkeklerden $(\overline{\mathrm{x}}=$ 116.527, $\mathrm{Sd}=17.688$ ) daha yüksek ortalamaya sahip olduğu kaydedilmiştir $[\mathrm{t}=3.151 ; \mathrm{P}<.01] . \mathrm{Bu}$ sonuca göre kadınlar erkeklerden daha fazla okuma alışkanlığına sahiptirler.

Merak-keşfetme ve Okuma Alışkanlığına Yönelik Tutum ölçeklerinden elde edilen puanlarla sınıf düzeyi değişkenin karşılaştırılması için t-test yapılmış ve elde edilen bulgular Tablo 5'te sunulmuştur.

Tablo 5

MK ve ÖRAKOT Puanlarının Sinıf Düzeyi Değişkenine Göre T-Testi Sonuçları

\begin{tabular}{lccccccc}
\hline Değişkenler & $\begin{array}{c}\text { Sinıf } \\
\text { Düzeyi }\end{array}$ & $\mathrm{N}$ & $\overline{\mathrm{x}}$ & $\mathrm{Sd}$ & $\mathrm{SE}$ & $\mathrm{t}$ & $\mathrm{p}$ \\
\cline { 2 - 8 } MK & 1 & 72 & 30.51 & 6.43 & .75 & -1.601 & .111 \\
\cline { 2 - 7 } & 3 & 150 & 32.04 & 6.79 & .55 & & \\
\hline ÖRAKOT & 1 & 72 & 119.93 & 17.61 & 2.07 & -1.708 & .089 \\
& 3 & 150 & 124.15 & 17.06 & 1.39 & & \\
\hline
\end{tabular}

Okul öncesi eğitimi ile sınıf öğretmenliği öğrencilerinin sınıf düzeyi dikkate alındığında MK puanı bakımından anlamlı düzeyde fark bulunmamıştır. Ancak 1. sınıf öğrencilerinin merak ve keşfetme algılarının $(\overline{\mathrm{x}}=30.51, \mathrm{Sd}=16.790)$ 3. sınıf öğrencilerinin algılarının ortalamasından $(\overline{\mathrm{x}}=32.04, \mathrm{Sd}=6.79)$ daha düşük olduğu tespit edilmiştir $[\mathrm{t}=-1,601 ; \mathrm{P}>.01]$. Ancak bu sonuç istatistiksel olarak anlamlı düzeyde değildir. Okuma alışkanlığına yönelik tutum açısından ise 1. sınıfta $(\overline{\mathrm{x}}=119.93, \mathrm{Sd}=7.61)$ öğrenim görmekte olan öğretmen adaylarının $3 . \sin ı f t a ~(\overline{\mathrm{x}}=124.15, \mathrm{Sd}=17.06)$ 
öğrenim görmekte olan katılımcılara göre daha düşük ortalamaya sahip olsa bile [t= 1,$708 ; \mathrm{P}>.01$ ] istatistiksel olarak anlamlı düzeyde değildir (Tablo 5).

MK puanları ile ÖRAKOT ölçeği puanları "kitap okuma alışkanlığı” değiş̧keni ile karşılaştırılmıştır. Yapılan t-testi analizi sonrasında elde edilen veriler Tablo 6'da sunulmaktadır.

Tablo 6

MK ve ÖRAKOT Puanlarının Kitap Okuma Alışkanlığı T-Testi Sonuçları

\begin{tabular}{|c|c|c|c|c|c|c|c|}
\hline Değişkenler & $\begin{array}{l}\text { Kitap okuma } \\
\text { alıșkanlığı }\end{array}$ & $\mathrm{N}$ & $\overline{\mathrm{x}}$ & $\mathrm{Sd}$ & SE & $\mathrm{t}$ & $\mathrm{p}$ \\
\hline \multirow[t]{2}{*}{ MK } & Çok okurum & 79 & 32.50 & 7.18 & .80 & \multirow[t]{2}{*}{1.587} & \multirow[t]{2}{*}{.114} \\
\hline & Az okurum & 143 & 31.02 & 6.38 & .53 & & \\
\hline \multirow[t]{2}{*}{ ÖRAKOT } & Çok okurum & 79 & 132.86 & 14.46 & 1.62 & \multirow[t]{2}{*}{7.134} & \multirow[t]{2}{*}{.000} \\
\hline & Az okurum & 143 & 117.21 & 16.25 & 1.35 & & \\
\hline
\end{tabular}

Öğretmen adaylarının MK puanları çok okuma $(\bar{x}=32.50, S d=7.18)$ ya da az okuma $(\overline{\mathrm{x}}=31.02, \mathrm{Sd}=6.38)$ durumuna göre anlamlı bir farklılık göstermemektedir $[\mathrm{t}=1,587 ; \mathrm{P}>.01]$. Diğer bir deyişle okuma alışkanlığının merak ve keşfetmeye yönelik düşünceyle ilgili olmadığını göstermektedir. Ancak okuma alışkanlığına yönelik tutumda çok okuduğunu ifade edenler $(\overline{\mathrm{x}}=132.860, \mathrm{Sd}=14.462)$ ile az okuduklarını ifade edenler $(\overline{\mathrm{x}}=117.423, \mathrm{Sd}=16.255)$ arasında, çok okuduğunu ifade edenler lehine anlamlı düzeyde fark bulunmuştur $[\mathrm{t}=7,134 ; \mathrm{P}<.01]$. Bu sonuç, çok okuduklarını söyleyen bireylerin gerçekten de daha çok okuma alışkanlığına sahip olduğunu göstermektedir.

Öğretmen adaylarının Merak-Keşfetme Ölçeği ile Okuma Alışkanlığına Yönelik Tutum Ölçeği puanları öğrenim gördükleri program değişkenine göre karşılaştırılmıştır. Yapılan t-testi analizinden elde dilen sonuçlar Tablo 7'de sunulmaktadır.

Tablo 7

MK ve ÖRAKOT Puanlarının Öğrenim Gördükleri Program Değişkenine Göre T-Testi Sonuçları

\begin{tabular}{|c|c|c|c|c|c|c|c|}
\hline Değişkenler & Program & $\mathrm{N}$ & $\overline{\mathrm{x}}$ & $\mathrm{Sd}$ & $\mathrm{SE}$ & $\mathrm{T}$ & $\mathrm{p}$ \\
\hline \multirow[t]{2}{*}{ MK } & $\begin{array}{l}\text { Okul Öncesi } \\
\text { Eğitimi } \\
\text { Programı }\end{array}$ & 104 & 31.23 & 6.56 & .64 & \multirow[t]{2}{*}{-.665} & \multirow[t]{2}{*}{.786} \\
\hline & $\begin{array}{l}\text { Sinıf } \\
\text { Öğretmenliği } \\
\text { Programı }\end{array}$ & 118 & 31.83 & 6.83 & .62 & & \\
\hline \multirow[t]{2}{*}{ ÖRAKOT } & $\begin{array}{l}\text { Okul Öncesi } \\
\text { Eğitimi } \\
\text { Programı }\end{array}$ & 104 & 119.42 & 17.37 & 1.70 & \multirow[t]{2}{*}{7.134} & \multirow[t]{2}{*}{001} \\
\hline & $\begin{array}{l}\text { Sinıf } \\
\text { Öğretmenliği } \\
\text { Programı }\end{array}$ & 118 & 125.74 & 16.79 & 1.54 & & \\
\hline
\end{tabular}

Okul öncesi eğitimi $(\bar{x}=31.23, S d=6.56)$ ile sınıf öğretmenliği $(\bar{x}=31.83, S d=6.83)$ öğrencilerinin merak ve keşfetme algılarına ilişkin puanlarında anlamlı düzeyde fark bulunmamıştır $[\mathrm{t}=-.665 ; \mathrm{P}>.01]$. Bu sonuca göre, merak ve keşfetme bakımından bölümler arasında benzerlik bulunmaktadır. Ancak okul öncesi eğitiminde öğrenim görmekte olan öğretmen adaylarının $(\overline{\mathrm{x}}=119.42, \mathrm{Sd}=17.37)$ sinıf öğretmenliğinde öğrenim görmekte olan öğretmen adaylarından $(\overline{\mathrm{x}}=125.74, \mathrm{Sd}=16.79) \quad$ okuma alışkanlıklarına yönelik tutum bakımdan daha az puana sahip olduğu görülmektedir. Sınıf öğretmenliği öğrencileri lehine anlamlı bir farklılık olduğu $[t=7.134 ; \mathrm{P}<.01]$. tespit edilmiştir (Tablo 7). Diğer bir değişle, sınıf öğretmenliği öğrencileri daha çok okuma yapmaktadir. 


\section{Sonuç, Tartışma ve Öneriler}

Araştırmadan elde edilen sonuca göre öğretmen adaylarının merak ve keşfetme algıları ile kitap okuma alıșkanlığına yönelik tutumları arasında anlamlı bir ilișki bulunmaktadır. Bu durum merak ve keşfetme gereksinimi duyan öğretmen adaylarının kitap okumaya yönelmeleri ile açıklanabilir. Birey daha fazla öğrenmeye ve bilgi edinmeye gereksinim duyduğunda büyük ölçüde kitaplardan yardım almakta ve kitap okumayı tercih etmektedir. Öğrenme isteği bireyi kitaplara yöneltmektedir. Birey öğrendikçe yaşama dair daha fazla merak duymakta ve okumaya daha fazla yönelmektedir. Merak düzeyinin yüksekliği, yaşantılara açık olan kişilerde daha fazladır. Önceki çalışmalar da bu yönde veriler sunmaktadır (Kashdan, Rose ve Fincham, 2004; Kashdan vd., 2009). Yaşantılara açık olmak daha fazla bilme, daha fazla kişi tanıma, daha fazla yeni şeyler keşfetmeyle ilişkili olmayı getirmektedir (Acun, Kapıkıran ve Kabasakal, 2013). Dolayısıyla yaşantılara açık olan ve bilme yönü güçlü olan bireylerin okumaya yönelik güçlü bir tutuma sahip olması beklenir. Yapılan bir çalışmada, merakı yüksek olanların okuduğunu anlama düzeylerinin de daha yüksek olduğu bulunmuştur (Gurning ve Siregar, 2017).

Araştırmada erkek öğrencilerin merak ve keşfetmeye ilişkin algılarının kız öğrencilere göre anlamlı düzeyde yüksek olduğu tespit edilmiştir. Bu durum toplumsal değerler açısından ele alınabilir. Türkiye'de erkeklerin gerek yetiştirilirken gerekse yetişkinlik sürecinde hemen her konuda daha fazla desteklendiği ve güven duygusunun beslendiğini söylemek mümkündür. Kadınlar için ise çoğunlukla itaat etmeye ilişkin düşünceler desteklenir. Bu durum erkek öğrencilerin merak ve keşfetmeye ilişkin algılarının daha fazla gelişmesini sağlamış olabilir. Araştırma yapılan üniversite Ege bölgesinde bulunmasına rağmen öğrencilerin Türkiye'nin değişik bölgelerinden geldiği ve çoğunlukla orta ve altı sosyo ekonomik düzeyde olduğu gözlerden uzak tutulmamalıdır. Ortaya çıkan sonuç Türkiye'nin küçük de olsa bir yansıması olarakdeğerlendirilebilir.

Araştırma sonuçlarına göre kitap okuma alışkanlığına yönelik tutumda kız öğrencilerin puanları erkek öğrencilerin puanlarına oranla anlamlı bir farklılık göstermektedir. Yani kız öğrencilerin okumaya yönelik tutumları erkek öğrencilerin tutumlarından daha yüksektir. Bu durum kız öğrencilerin öğrenmek için daha fazla kitaba yönelmeleri ile açıklanabilir. Erkek öğrenciler öğrenme isteği karşısında kitaptan daha farklı kaynaklara da yönelebilmektedir. Yılmaz ve Benli (2010), 400 katılımcı ile yaptıkları araştırmada öğretmen adaylarının okumaya yönelik tutumlarını farklı değişkenlere göre değerlendirmiştir. Kadın öğretmen adaylarının okumaya yönelik tutumlarının erkek öğretmen adaylarının tutumlarına göre anlamlı düzeyde farklı olduğunu tespit etmiştir. Özdemir, Özdemir ve Kaya (2015), 412 öğretmen adayı ile yaptı̆̆ araştırmada okumaya yönelik tutumları farklı değişkenler açısından değerlendirmiştir. Araştırma sonucuna göre kadın öğrenciler lehine anlamlı bir farklılık olduğu tespit edilmiştir. Bu konuda yapılan birçok araştırmada kadın öğretmen adaylarının okumaya yönelik tutumlarının erkek öğretmen adaylarına göre anlamlı bir farklılık gösterdiği tespit edilmiştir (Batur, Gülveren ve Bek, 2010; Duman ve Gökmen, 2018; Odabaş, Odabaş ve Polat, 2008; Özbay, Bağc1, Uyar, 2008; Saracaloğlu, Bozkurt ve Serin, 2003; Saracaloğlu, Yenice ve Karasakaloğlu, 2006; Yalınkılıç, 2007). Akbaba (2017) ise 148 öğretmen adayı ile yaptığı çalışmada cinsiyet değişkenine göre gruplar arasında anlamlı bir farklılık olmadığını tespit etmiştir.

Araştırma sonuçlarına göre hem merak ve keşfetmede hem de okuma alışkanlığına yönelik tutumda sınıf düzeyi değişkeni göz önüne alındığında 1. sınıflar ile 3. sınıflar arasında anlamlı bir farklılık bulunmamaktadır. Her iki grubun da puanları birbirine yakındır. Özbay, Bağcı ve Uyar (2008) Türkçe Öğretmenliği Bölümünde öğrenim görmekte olan öğretmen adayları ile yaptığı araştırmada okumaya yönelik tutumların sınıf düzeyine göre değişmediğini tespit etmiştir. Sağlam, Suna ve Çengelci de (2008) sınıf öğretmenliği bölümünde öğrenim görmekte olan öğretmen adaylarının okuma alışkanlıklarının sınıf düzeyi değişkenliğine göre farklılaşmadığını tespit etmiştir.

Araştırmadan elde edilen sonuçlara göre öğretmen adaylarının merak ve keşfetmeye ilişkin algıları çok okuma ve az okuma alışkanlığı göz önüne alındığında anlamlı bir farklılık göstermemektedir. Az okuduğunu ve çok okuduğunu ifade eden öğrencilerin merak ve keşfetmeye ilişkin algıları benzerdir. Öğrencilerin çok okuyor olması merak ve keşfetme istekliliklerinin de 
yüksek olduğu anlamına gelmemektedir. Merak değerlerinin çok da fazla desteklenmediği, eleştirel düşüncenin oldukça geri planda bırakıldığı bir toplumda okuma alışkanlığının iyi düzeyde olmasiyeterli görülmeyebilir.

Okuma alışkanlığına yönelik tutumun çok okuyan öğrencilerde az okuyanlara göre daha yüksek olduğu tespit edilmiştir. Okuma alışkanlığına yönelik olumlu tutum geliştirmiş olan öğrencilerin okuma alışkanlığının ve kitap sevgisinin yüksek olması oldukça olağan karşılanabilir. Öğretmen adaylarının okumaya yönelik tutumlarının yüksek olması onları kitaba yöneltmektedir. Kennedy (2014) öğretmen adayları ile yaptığı araştırmada öğretmen adaylarının okumaya yönelik olumlu duygular ifade etmelerine rağmen araştırmanın nicel boyutunda okumaya yönelik tutumlarının düşük olduğunu tespit etmiştir. Pillai (2015) çevrimiçi ortamda 90 öğretmen adayı ile yaptığı araştırmada katılımcıların okuma alışkanlıklarının yeterli olmadığını tespit etmiştir. Benzer bulgular (Applegate ve Applegate, 2004; Dengler, 2018; Nathanson, Pruslow ve Levitt, 2008) başka araştırmalarda da tespit edilmiştir.

Okul öncesi eğitimi programında öğrenim gören öğrencilerle sınıf eğitimi programında öğrenim görmekte olan öğrencilerin merak ve keşfetme algıları arasında anlamlı bir farklılık olmadığı belirlenmiştir. Ancak okuma alışkanlığına yönelik tutumda sınıf öğretmenliği öğrencilerinin puanlarının okul öncesi öğretmenliği öğrencilerine göre anlamlı bir fark gösterdiği tespit edilmiştir. Okul öncesi eğitimi programında yer alan dersler ağılıklı olarak oyuna ve etkinlik yapmaya dayanmaktadır. Sınıf eğitimi programında yer alan dersler ise daha fazla teori içermektedir. Bu durum öğrencilerin okumaya yönelik tutumlarını olumlu yönde etkileyebilmektedir. Özdemir, Özdemir ve Kaya (2015), öğretmen adayları ile yaptıkları araştırmada öğrenim görülen program değişkenine göre okul öncesi eğitimi bölümü lehine anlamlı bir farklılık tespit etmiştir.

Araştırma sonuçlarına göre şu öneriler geliştirilmiştir. Öğretim elemanları derslerde yaptıkları tartışmalar ile öğrencileri hem kitap okumaya özendirmeli hem de onların merak ve keşfetme dugularını desteklemelidir. Özellikle kız öğrencilerin merak ve keşfetmeye yönelik duyguları derslerde yapılacak tartışmalarla ön plana çıkarılmalaı bu konuda pozitif ayrımcılık yapılmalıdır. Özellikle kırsal bölgeden gelen kız öğrencilerin merak ve keşfetme duygularını ön plana çıkarıcı çalışmalara yer verilmelidir. Bu öğrencilerin ilerleyen yıllarda kendi öğrencilerini yetiştireceği unutulmamalıdır. Öğretmen yetiştiren tüm programlarda olduğu gibi okul öncesi eğitimi programında öğrenim gören öğrencilerin okuma alışkanlıklarını destekleyici çalışmalara yer verilmelidir.

Açıklama: Bu çalışmanın bir kısmı İzmir'de 2- 4 Mayıs 2019 tarihleri arasında düzenlenmiş olan "1st International Science, Education, Art \& Technology Symposium" adlı bilimsel toplantıda sözlü bildiri olarak sunulmuştur. 


\section{Kaynaklar}

Acun, N., Kapıkıran, Ş. ve Kabasakal, Z. (2013). Merak ve keşfetme ölçeği II: Açımlayıcı ve doğrulayıcı faktör analizleri ve güvenirlik çalışması. Türk Psikoloji Yazıları, 16 (31), 74-85.

Akande, S. O. and Oyedapo, R. O. (2018). Developing the reading habits of secondary school students in Nigeria: The way forward. International Journal of Library Science, 7(1), 15-20.

Akbaba, R. S. (2017). Türkçe öğretmeni adaylarının okuma alışkanlıkları ve okumaya yönelik tutumlar1. Turkish Studies, 12(18), 35-52.

Applegate, A. J. and Applegate, M. D. (2004). The Peter Effect: Reading habits and attitutes of preservice teachers. International Reading Association, 554-563.

Batur, Z. Gülveren, H. ve Bek, H. (2010). Öğretmen adaylarının okuma alışkanlıkları üzerine bir araştırma: Uşak Eğitim Fakültesi örneği. Uşak Üniversitesi Sosyal Bilimler Dergisi, 3(1), 32-49.

Büyüköztürk, Ş., Kılıç Çakmak, E., Akgün, Ö. E., Karadeniz, Ş. ve Demirel, F. (2012). Bilimsel araştırma yöntemleri. Ankara: Pegem A Akademi.

Chaiklin, H. (2011). Attitudes, behavior, and social practice. The Journal of Sociology \& Social Welfare, 38(1), 31-54.

Chery, K. (2019). Attitudes and Behavior in psychology. https://www.verywellmind.com/attitudeshow-they-form-change-shape-behavior-2795897 11.05.2019 tarihinde erişilmiştir.

Chettri, K. and Rout, S. K. (2013). Reading habitsan overview. IOSR Journal Of Humanities And Social Science (IOSR-JHSS), 14(6), 13-17.

Dengler, K. A. (2018). Aliterate pre-service teachers' reading histories: An exploratory multiple case study. Doctoral Thesis. Binghamton University State University, New York.

Duman, B. ve Gökmen, T. (2018). Öğretmen adaylarının okumaya yönelik tutumlarının incelenmesi. Bartın Üniversitesi Eğitim Araştırmaları Dergisi, 2(2), 13-22.

Edmunds, K., and Tancock, S. (2003). The effects on the reading motivation of fourth-grade students. Reading Research and Instruction, 42(2), 17-38.

Eren, A. (2009). Bilgi kaynaklı merak ve başarı amaçları arasındaki ilişkinin incelenmesi. Eurasian Journal of Educational Research, 36, 129-144.

Gerber, O. and Hoelson, C. N. (2011). Curiosity and coping with uncertainty among psychologists-intraining. New Voices in Psychology, 7(1) 3-18.

Gurning, B. and Siregar, A. (2017). The effect of teaching strategies and curiosity on students' achievement in reading comprehension. English Language Teaching, 10(11), 191-198.

Guthrie, J., Wigfield, A. and VonSecker, C. (2000). Effects of integrated instruction on motivation and strategy use in reading. Journal of Educational Psychology, 92(2), 331-341.

Kağıtçıbaşı, Ç. (2006). Yeni insan ve insanlar sosyal psikolojiye giriş. İstanbul: Evrim Yayınevi.

Karahan, B. Ü. (2018). Okumaya yönelik tutum ölçeği: Ölçek geliştirme çalışması. Kastamonu Üniversitesi Kastamonu Ë̆itim Dergisi, 26(1), 67-73. 
Kashdan, T. B., Gallagher, M. W., Silvia, P. J., Winterstein, B. P., Breen, W. E., Terhar, D.T. and Steger, M. F. (2009). The curiosity and exploration inventory-II: Development, factor structure, and psychometrics. Journal of Research in Personality, 43, 987-998.

Kashdan, T. B. and Silvia, P. J. (2009). Curiosity and interest: The benefits of thriving on novelty and challenge. In C. R. Synder and S. J. Lopez (Eds.), Oxford handbook of positive psychology (p. 367-375). USA: Oxford University Press.

Kashdan, T. B., Rose, P. and Fincham, F. D. (2004). Curiosity and exploration: Facilating positive subjective experiences anda personal growth opportunities. Journal of Personality Assesment, 82(3), 291-305.

Kashdan, T. B., Stiksma, M. C., Disabato, D. J., McKnight, P. E., Bekier, J., Kaji, J. and Lazarus, R. (2018). The five-dimensional curiosity scale: Capturing the bandwidth of curiosity and identifying four unique subgroups of curious people. Journal of Research in Personality, 73, 130149.

Kennedy, A., L., S. (2014). Reading habits and attitudes of pre-service teachers: A case study. Doctoral Thesis, Widener University, Pennsylvania.

Korkmaz, B. (2008). Okuma Öğretimi, A. Tazebay ve S. Çelenk (Ed.) Türkçe Öğretimi içinde (s. 70127). Ankara: Maya Akademik Yayıncılık.

Kushmeeta, C. and Rout, S. K. (2013). Reading habits-an overview. Journal of Humanities and Social Sciences (IOSR-JHSS), 14(6), 13-17.

Mckool, S. S. and Gespass, S. (2009). Does Johnny's reading teacher love to read? How teachers' personal reading habits affect instructional practices. Literacy Research and Instruction, 48(3), 264-276.

Nathanson, S., Pruslow, J. and Levitt, R. (2008). The reading habits and literacy attitudes of in-service and prospective teachers results of a questionnaire survey. Journal of Teacher Education, 59(4), 313-321.

Odabaş, H., Odabaş, Z. Y. ve Polat, C. (2008). Üniversite öğrencilerinin okuma alışkanlığı: Ankara Üniversitesi örneği. Bilgi Dünyasl, 9(2), 431-465.

Oğuzkan, F. (1997). Çocuk edebiyatı. Ankara: Emel Matbaacılık.

Olson, K., Camp, C. and Fuller, D. (1984) Curiosity and need for cognition. Psychological Reports, 54(1), 71-74.

Özbay, M., Bağcı, H. ve Uyar, Y. (2008). Türkçe öğretmeni adaylarının okuma alışkanlığına yönelik tutumlarının çeşitli değiş̧kenlere göre incelenmesi. Inönü Üniversitesi Eğitim Fakültesi Dergisi, $15,117-136$.

Özdemir, S. ve Akkaya, N. (2014). Ortaöğretim öğrencileri için okumaya yönelik tutum ölçeği, geçerlik ve güvenirlik çalışması. Milli Eğitim Dergisi, 203, 55-73.

Özdemir, O., Özdemir, M. ve Kaya, B. (2015). Öğretmen adaylarının kitap okuma alışkanlıklarının incelenmesi. Trakya Üniversitesi Sosyal Bilimler Dergisi, 17(2), 219-233.

Pillai, P. R. (2015). Assessing reading habits of pre-service teachers in this electronic era. International Journal of Innovation and Research in Educational Sciences, 2(2), 69-71. 
Sağlam, M., Suna, Ç. ve Çengelci, T. (2008). Öğretmen adaylarının okuma alışkanlıklarını etkileyen etmenlere ilişkin görüş ve öneriler. Milli Eğitim Dergisi, 178, 8-23.

Saracaloğlu, A. S., Bozkurt, N. ve Serin, O. (2003). Üniversite öğrencilerinin okuma ilgileri ve alışkanlıklarını etkileyen faktörler. Eğitim Araştırmaları Dergisi, 4(12),149-150.

Saracaloğlu, A.S., Yenice, N. ve Karasakaloğlu, N. (2006). Öğretmen adaylarının iletişim ve problem çözme becerileri ile okuma ilgi ve alışkanlıkları arasındaki ilişki. III. Uluslararası Öğretmen Yetiştirme Sempozyumu, s. 1-23.

Shen. L. (2006). Computer technology and college students' reading habits. Chia-nan annual bulletin, $32,559-572$.

Small, R. V. (2009). Reading incentives that work: No-cost strategies to motivate kids to read and love it!. School Library Media Activities Monthly, 25(9), 27-31.

Smith, M. C. (1990). A longitudinal investigation of reading attitude development from childhood to adulthood. Journal of Educational Research, 83(4), 215-219.

Stanfield, G. M. (2006). Incentives: The effects on reading attitude and reading behaviors of thirdgrade students. Master Thesis. Georgia College and State University, Milledgeville, Georgia.

Susar Kırmızı, F. (2012). Öğretmen adaylarının kitap okuma alışkanlığına yönelik tutum ölçeği: Geçerlik ve güvenirlik çalışması. Turkish Studies, 7(3), 2353-2366.

Tekbıyı, A. (2015). Kuramdan Uygulamaya Eğitimde Bilimsel Araştırma Yöntemleri. M. Metin, (Ed.). İlişkisel Araştırma Yöntemi (s. 101-103). Ankara: Pegem Akademi.

Wagner, S. (2002). The reading habits of teams. Journal of Reading Today, 46, 3-4.

Yalınkılıç, K. (2007). Türkçe öğretmen adaylarının okumaya ilişkin tutum ve görüşleri. Uluslararası Sosyal Araştırmalar Dergisi, 1(1), 225-241.

Yılmaz, B. (1993). Okuma alışkanlığında halk kütüphanelerinin rolü. Ankara: Kültür Bakanlı̆̆1 Kütüphaneler Genel Müdürlüğü.

Yılmaz, M. ve Benli, N. (2010). Sınıf öğretmeni adaylarının okuma alışkanlığına yönelik tutumlarının bazı değişkenlere göre incelenmesi, Erzincan Eğitim Fakültesi Dergisi, 12(1), 281-291. 


\section{Extended Abstract}

\section{Introduction}

Curiosity has been the focus of attention as a remarkable feature in personality psychology. Curiosity is critical for human survival and growth. Curiosity can be defined as the desire to follow, recognize and discover uncertain, complex and new events. Curiosity is a powerful motive inherent in all living things. The motive of curiosity is to try to understand a situation with learning potential. Reading is one of the easiest and most effective ways of learning for an individual who has undergone an educational process from birth. Contemporary societies have high reading rates and experience positive aspects of reading in all areas. Underdeveloped societies cannot be productive in all areas of life as well as science and art. Because reading individuals are more successful in seeing the inner side of events, criticizing, questioning, seeking rights and respecting the differences of others. Therefore, the development of reading habits is very important for advancing towards becoming a modern society. The aim of this study is to investigate the relationship between the perceptions of prospective and disciplinary teachers' attitudes towards reading habits and their attitudes towards reading habits in the faculty of education, preschool and classroom teacher programs. On the other hand, the relationship between prospective teachers' perceptions of curiosity and discovery and reading habits were evaluated in terms of different variables.

\section{Method}

In this study, exploratory correlational model was adopted. Correlational research is a study in which the relationships between two or more variables are examined without interfering with these variables in any way. This study was carried out in the departments of classroom education $(\mathrm{n}=118)$ and preschool education $(\mathrm{n}=104)$ of Pamukkale University Faculty of Education in the spring term of 2018-2019 academic year. The data of the study were collected from 222 prospective teachers, 72 of whom were first grade (32\%) and 150 of second grade (68\%). In obtaining the research data, Curiosity and Exploration Scale II developed by Kashdan et al. (2009) and Attitude Scale for Prospective Teachers' Reading Habits (ÖRAKOT) developed by Susar-Kırmızı (2012). In this study, pre-service teachers' attitudes towards reading habits were examined with descriptive analyzes such as correlation analysis, cronbach's alpha, kurtosis, skevness, t-test, mean and standard deviation.

\section{Result}

The t-test was used to determine whether there was a difference between the genders in terms of curiosity and reading habits attitude scores. In terms of curiosity scores of teacher candidates, it was found that males $(33.781, \mathrm{Sd}=6.190)$ had higher scores than women $(\overline{\mathrm{x}}=30.485, \mathrm{Sd}=6.536)[\mathrm{t}$ $(4.283)=\mathrm{P}<.001]$. When the class level of preschool and classroom teacher students was taken into consideration, no significant difference was found in terms of curiosity score. However, the curiosity and discovery perceptions of 1 st grade students $(\overline{\mathrm{x}}=30,51, \mathrm{Sd}=16,790)$ were found to be lower than the average of 3rd grade students' perceptions $(\overline{\mathrm{x}}=32.04, \mathrm{Sd}=6.79)$. The curiosity and discovery scores of the prospective teachers do not show a significant difference according to the status of over reading $(\overline{\mathrm{x}}=32.50, \mathrm{Sd}=7.18)$ or low reading $(\overline{\mathrm{x}}=31.02, \mathrm{Sd}=6.38)$. There was no significant difference between the pre-school $(\overline{\mathrm{x}}=31.23, \mathrm{Sd}=6.56)$ and classroom teacher $(\overline{\mathrm{x}}=31.83, \mathrm{Sd}=6.83)$ students' perceptions of curiosity and discovery. However, it is seen that preschool students $(\overline{\mathrm{x}}=$ $119.42, \mathrm{Sd}=17.37)$ have less points than their primary school students $(\mathrm{x}=125.74, \mathrm{Sd}=16.79)$ in terms of attitude towards reading habits.

\section{Discussion and Conlusion}

According to the results of the research, there is a significant relationship between the preservice teachers' perceptions of curiosity and discovery and their attitudes towards reading. This situation can be explained by the prospective teachers who need curiosity and discovery. When an 
individual need to learn more and obtain information, he or she mostly gets help from books and prefers to read. The desire to learn leads the individual to books. The more individuals learn, the more they are curious about life and the more they read. In the study, it was found that male students' perceptions of curiosity and discovery were significantly higher than female students. This situation can be handled with social values. In our country, you can say that the fact that men are both in the upbringing and adulthood of the world is more supported and the sense of trust is fed. For women, the thoughts that you are obeying are supported. This may lead to further development of a curious and exploratory perception in men. 